\title{
Hemodynamic Changes of Hepatic Veins as Predictors of Large Oesophageal Varices in Liver Cirrhotic Patients
}

\author{
Taghrid M. Abdallah ${ }^{1}$, Wael El Shelfa ${ }^{2}$, Saeed B. El-Sayed ${ }^{3}$,Haitham \\ Dawoud $^{3}$ \\ ${ }^{1}$ Tropical Medicine Department, Faculty of Medicine, Zagazig University, Egypt. \\ ${ }^{2}$ General Surgery Department, Faculty of Medicine, Zagazig University, Egypt. \\ ${ }^{3}$ Radiology Department, Faculty of Medicine, Zagazig University, Egypt.
}

Corresponding Author Taghrid M. Abdallah

E mail: tagkomy@gmail.com

Key words: Liver cirrhosis- esophageal varicesOesophagogastroduod enoscopy-Color Doppler Abdominal Ultrasound- hepatic vein.
Background and study aim: Oesophageal varices (OV) are morbid and mortal complications of portal hypertension. Oesophagogastroduodenoscopy (OGD) is the main diagnostic yet semi- invasive tool; different non-invasive methods were developed for early prediction and assessment of OV yet not fully evaluated. This work aims at assessment of changes of hepatic venous wave patterns as early predictors of large $\mathrm{OV}$ in cirrhotic patients without history of variceal bleeding.

Patients and methods: A number of 50 previously diagnosed liver cirrhotic patients were subjected to detailed history taking. After exclusion criteria only 46 patients were included in the study. They were subjected to routine investigations, OGD, abdominal ultrasound (US) and

\section{INTRODUCTION}

Oesophageal varices $(\mathrm{OV})$ are one of the most awful complications of liver cirrhosis. Its incidence in cirrhotic patients ranges between $60-80 \%$. Upper gastrointestinal bleeding (UGB) - caused mainly by rupture of $\mathrm{OV}$ and to less extent by gastric varices - is disastrous implying a mortality rate of $17-57 \%$ of these prone patients [1]. OV are the direct result of portal hypertension and their presence is usually correlated with the severity of liver disease. About $45 \%$ of patients with Child-Pugh A cirrhosis were found to have $\mathrm{OV}$ while this percentage jumps to $85 \%$ in those with Child- Pugh C [2]. The frequency of bleeding from large $\mathrm{OV}$ is $50-53 \%$ while that of small $\mathrm{OV}$ is $5-18 \%$ that can be attributed to the increased variceal wall tension in large OV $[3,4]$.
Color Doppler studying of the hepatic veins (HV).

Results: Out of the total number (46 liver cirrhotic patients included in the study), the triphasic waves were detected in $(26.1 \%)$, biphasic waves in $(43.5 \%)$ and monophasic waves in $(30.4 \%)$. Small varices were detected in $(65.2 \%)$, while large varices were detected in (34.8 $\%$ ). The sensitivity of loss of the triphasic waveform in detecting large varices was high $(93.8 \%)$, specificity was $(36.7 \%)$, the positive predictive value was $(44.1 \%)$ and the negative predictive value was high $(91.7 \%)$.

Conclusion: The loss of hepatic venous triphasic waveform - detected by Color Doppler Abdominal Ultrasound Study- is a weak predictor of large $\mathrm{OV}$ in liver cirrhotic patients without history of variceal bleeding.

Because of the dramatic destiny of $\mathrm{OV}$, it is highly recommended to screen all liver cirrhotic patients for the presence of $\mathrm{OV}$ at the time of diagnosis and periodically by Oesophagogastroduodenoscopy

(OGD). If $\mathrm{OV}$ were not detected in the first endoscopic screening, reevaluation after three years is recommended in compensated liver cirrhotic patients and annually in decompensated liver cirrhotic patients [5-7]. OGD is the gold standard diagnostic method of OV. However, many drawbacks were recorded against OGD including its invasiveness, risk of perforation, aspiration and bacteremia. Moreover, it is not accepted by many patients $[8,9]$ and the cost of repeated screening stressed the need to develop non- invasive techniques for early prediction of recent, developing and large $\mathrm{OV}$ to reduce the frequency of 
OGD so that it can be preserved for highly suspected cirrhotic patients [10,11]. Many clinical, radiological and chemical predictor methods were advocated either separately or in combinations such as platelet count, studying the spleen with portal vein diameter and ChildPaugh class [12-15].

Multiple Doppler indices were suggested to assess the severity of portal hypertension in cirrhotic patients including the study of hepatic venous waveform changes [16-19]. The normal hepatic venous waveform pattern is triphasic (two negative waves and one positive wave) according to variations in the central venous pressure of the cardiac cycle, but it changes to the biphasic and monophasic pattern in cirrhotic patients (Fig. 1). These changes are attributed to the progressive loss of hepatic compliance. Monophasic waves were found to correlate with the severity of liver disease (high scores of Child-Pugh classification) and poor survival rate [20-23].

This work aims at evaluating the changes of hepatic venous waveform as early predictors of large $\mathrm{OV}$ in liver cirrhotic patients without history of variceal bleeding.

\section{PATIENTS AND METHODS}

This is a collaborated work between Tropical Medicine, General Surgery and Radiology Departments, Faculty of Medicine, Zagazig University.

Inclusion criteria: The already diagnosed liver cirrhotic patients attending to Tropical outpatient clinic or admitted in the ward of Tropical Medicine Department, Zagazig University Hospitals were included in the study. The diagnosis of liver cirrhosis was already established by clinical approach, laboratory investigations, routine abdominal ultrasound, endoscopic data and liver biopsy.

Exclusion criteria: Patients with history of variceal bleeding, hepatocellular carcinoma, portal vein thrombosis, endoscopic variceal ligation or sclerotherapy were excluded from the study. Patients with cardiac, respiratory or renal diseases or those under treatment with drugs affecting portal haemodynamics (eg. propranolol) were also excluded.

All included patients were subjected to thorough history taking, clinical examination, routine laboratory investigations, routine abdominal US and Child- Pugh classification. Then they were subjected to:

*Oesophagogastroduodenoscopy (OGD): OV were graded according to the guidelines of the American Association for the Study of Liver Diseases (AASLD) considering them small if less than $5 \mathrm{~mm}$ diameter and large if more than 5 mm diameter [24].

*Abdominal ultrasound examination: It was done according to the following steps.

1. After 6-8 hours fasting, all patients were subjected to routine B- mode abdominal ultrasound (US) examination of the liver assessing the size, echogenicity, border irregularity and exclusion of focal lesions.

2. Doppler ultrasound using the $3.5 \mathrm{MHz}$ convex probe (GE, Logic III US, expert, USA). The portal vein first assessed for exclusion of thrombosis then the probe was placed in the right intercostal spaces for tracing of the hepatic veins. Color Doppler was used to identify the pattern of blood flow in the hepatic veins.

3. Spectral analysis of the hepatic venous waveform pattern was obtained from the right hepatic vein $3-6 \mathrm{~cm}$ from its junction with inferior vena cava [25]. The middle hepatic vein was used for spectral analysis in some cases instead of tracing of the right hepatic vein.

4. Doppler study of waveforms of hepatic veins was recorded for at least 5-10 seconds during quiet breathing or at the end-inspiratory point with breath holding if quiet breathing is not possible. Three records were usually taken for each patient.

5. Color Doppler flow mapping was interpreted as a blue hepatic vein waveform indicating flow away from the US probe and a red hepatic vein waveform indicating flow toward the US probe.

6. Hepatic venous waveforms were classified into:

- Triphasic (normal) waves with reversed flow in at least one phase. It is considered triphasic if recognized in at least one of three records.

- Biphasic waves without reversed flow and with or without diminished phasic oscillation. 
It is considered biphasic if recognized in at least one of three records.

- Monophasic or flat pattern with or without fluttering. It was considered if the three records are monophasic.
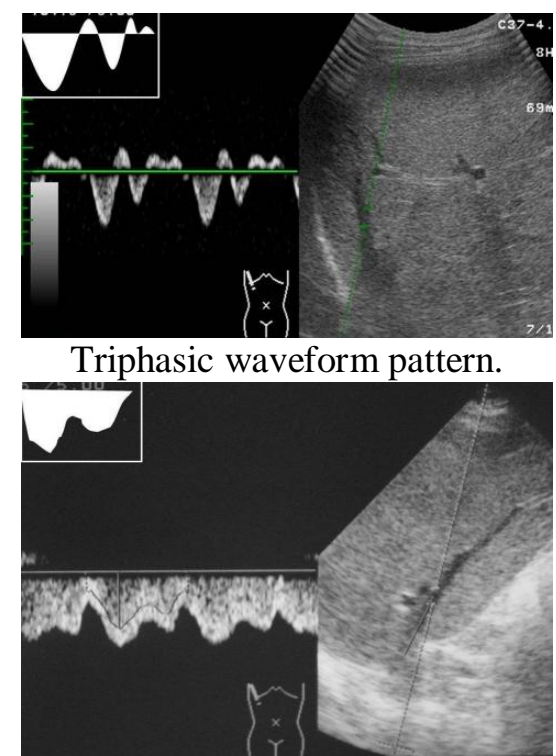

Biphasic waveform pattern.

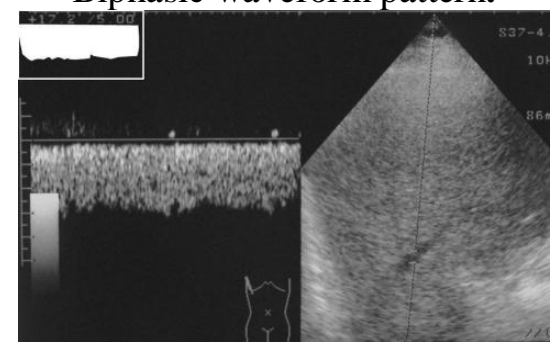

Monophasic waveform pattern.

Figure (1): Hepatic venous waveform pattern

\section{Statistical Analysis:}

The relation between US wave and OV Size and some factors (age, sex, duration of illness, severity of liver disease) were done using the Pearson chi square test. The role of lost triphasic pattern in predicting large varices was determined by sensitivity, specificity, positive and negative predictive values and Kappa (K) measure of agreement.

$$
\begin{aligned}
& \text { Positivepredictive value }=\frac{\text { True positive }}{\text { True positive }+ \text { false positive }} \\
& \text { Negative predictive value }=\frac{\text { True negativee }}{\text { True negative }+ \text { false negative }}
\end{aligned}
$$

Probability equal or less than 0.05 is considered significant. Data analysis was done using Statistical package for social sciences (SPSS, version 15.0; Chicago, IL, USA).

\section{Ethical approval:}

Informed consent was taken from each patient. The research protocol was duly approved by the ethical committee of Zagazig University Hospitals.

\section{RESULTS}

A total number of 50 patients were suggested for the study. After exclusion criteria, 46 patients were included in the study. Males were 24patients $(52.2 \%)$, while females were 22 patients $(47.8 \%)$. Their ages ranged between 19 and 62 years $(35.17 \pm 13.9)$. According to ChildPugh classification, Child-Pugh class A included 24 patients $(52.2 \%)$, Child- Pugh class B included 10 patients (21.7\%) and Child- Pugh class C included 12 patients (26.1\%). The duration of illness was less than 4 years in 17 patients $(37 \%), 4-8$ years in 17 patients $(37 \%)$ and more than 8 years in 12 patients $(26 \%)$. Patients with small OV were 30 patients $(65.2 \%)$ while those with large OV were 16(34.8\%). Patients with monophasic waves were 14 (30.4\%), biphasic waves were $20(43.5 \%)$ and those with triphasic waves were $12(26.1 \%)$ (Table 1).

Table (2) showed that large OV were mainly represented among patient age group 25- 50 years while small OV were mainly represented among patients less than 25 years. Small OV were more prevalent than large $\mathrm{OV}$ among all age groups. However the differences were nonsignificant.

Large OV were mainly represented among patients with duration of illness more than 8 years, while small OV were mainly represented among patients with duration of illness less than 4 years. Large OV were more prevalent than small OV among patients with duration of illness more than 8 years, while small OV were more prevalent than large $\mathrm{OV}$ among patients with duration of illness 4-8 years or less than 4 years. The differences were significant.

Large OV were more prevalent among ChildPugh class $\mathrm{C}$ patients, while small OV were more prevalent among Child- Pugh class A patients. Large OV were more prevalent among Child-Pugh class B and C patients, while small OV were more prevalent among Child-Pugh 
class A patients. The differences were highly significant.

There was a non - significant difference regarding the size of $\mathrm{OV}$ between males and females.

Table (3) showed that triphasic waves were the most prevalent pattern among Child-Pugh class A patients, while biphasic waves were the most prevalent pattern among Child- Pugh class B and $\mathrm{C}$ patients. The differences were significant.

Biphasic waves were the most prevalent pattern among males, while triphasic waves were the most prevalent pattern among females. However the differences were non- significant.

Monophasic waves were the least prevalent pattern among patients younger than 25 years, while biphasic waves were the most prevalent pattern among patients 25- 50 years. Monophasic and biphasic waves were equally presented in patients older than 50 years, while triphasic waves were not encountered among this age group. All the differences were non- significant.

Biphasic waves were the most prevalent pattern among patients with duration of illness less than 4 years, while monophasic waves were the least prevalent pattern among patients with duration of illness 4- 8 years and biphasic waves were the most prevalent pattern among patients with duration of illness more than 8 years and no triphasic waves were encountered among this group. However, the differences were nonsignificant.

Biphasic waves were the most prevalent pattern among patients with small OV, while monophasic waves were the least prevalent pattern among patients with large $\mathrm{OV}$ and Biphasic and triphasic waves were equally presented in this group. All the differences were non-significant.

Table (4) shows that the sensitivity of monophasic waves to detect large OV was 42.9 $\%$, while specificity was $57.9 \%$. The positive predictive value (PPV) was $85.7 \%$, while the negative predictive value (NPV) was $91.7 \%$.

The sensitivity of biphasic waves to detect large OV was $90 \%$, while the specificity was $50 \%$. The PPV was $45 \%$, while the NPV was $91.7 \%$.

The sensitivity of loss of triphasic waves (presence of monophasic or biphasic waves) to detect large OV was $93.8 \%$, while the specificity was $36.7 \%$. The PPV was $44.1 \%$, while the NPV was $91.7 \%$.

The overall result was the non- significant agreement between the results of OGD findings and the results of Doppler Abdominal US. 
Table (1): Distribution of age, sex, duration of liver cirrhosis, Child- Pugh classification, OV size and Doppler US waveform among studied patients.

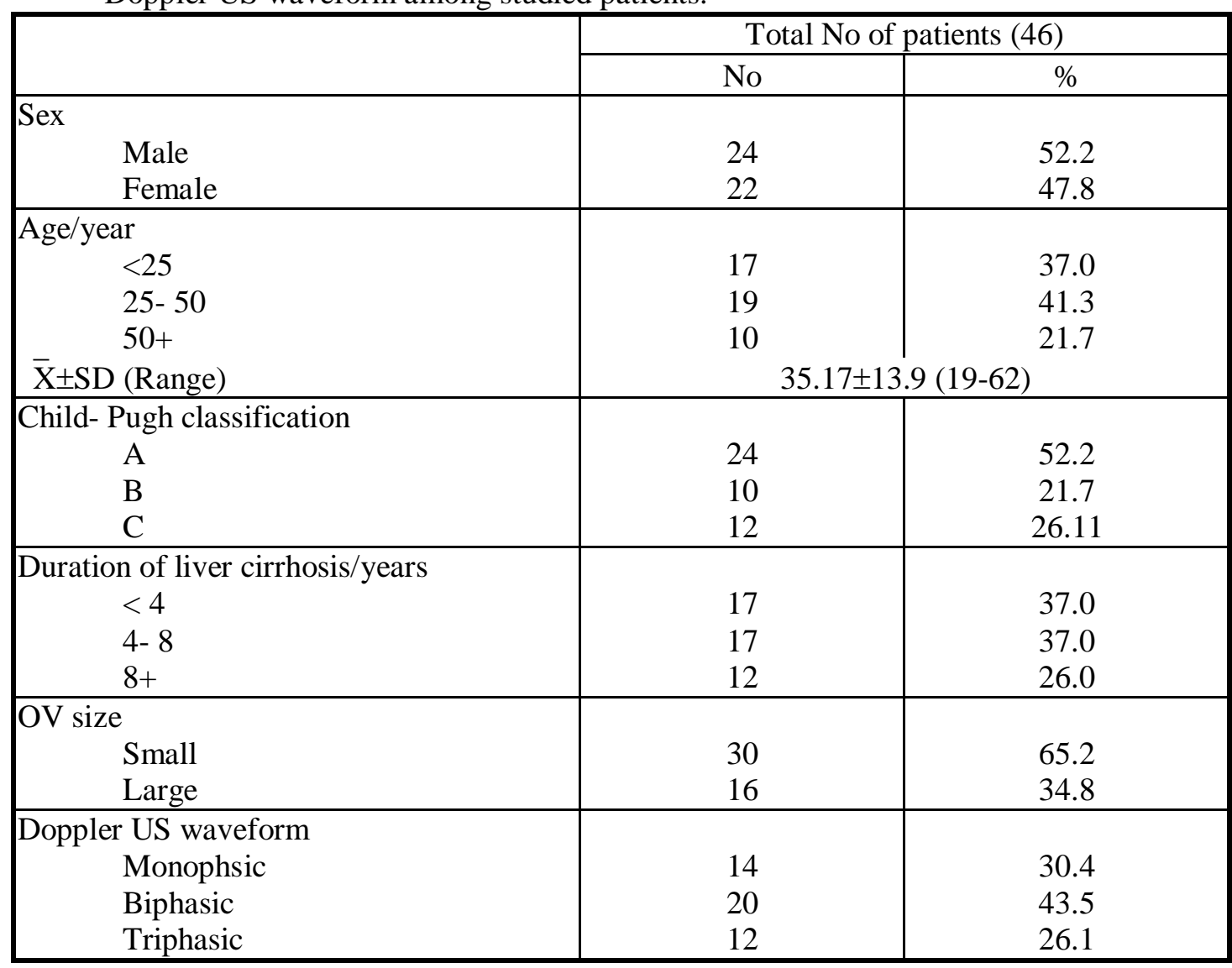

Table (2): Relation between age, sex, duration of liver cirrhosis, child- Pugh classification and OV size.

\begin{tabular}{|c|c|c|c|c|c|c|}
\hline \multirow[t]{2}{*}{ Total $=46$ patients } & \multicolumn{2}{|c|}{ Large } & \multicolumn{2}{|c|}{ Small } & \multirow{2}{*}{$\mathrm{X}^{2}$} & \multirow{2}{*}{ P-value } \\
\hline & No (16) & $(34.8 \%)$ & No (30) & $(65.2 \%)$ & & \\
\hline \multicolumn{7}{|l|}{ Age/years } \\
\hline$<25$ & 5 & 29.4 & 12 & 70.6 & \multirow{3}{*}{0.76} & \multirow{3}{*}{0.68} \\
\hline $25-50$ & 8 & 42.1 & 11 & 57.9 & & \\
\hline $50+$ & 3 & 30.0 & 7 & 70.0 & & \\
\hline \multicolumn{7}{|l|}{$\begin{array}{l}\text { Duration of liver cirrhosis } \\
\text { /years }\end{array}$} \\
\hline$<4$ & 3 & 17.6 & 14 & 82.4 & \multirow{3}{*}{7.79} & \multirow{3}{*}{$0.02 *$} \\
\hline 4- 8 & 5 & 29.4 & 12 & 70.6 & & \\
\hline $8+$ & 8 & 66.7 & 4 & 33.3 & & \\
\hline \multicolumn{7}{|l|}{ Child- Pugh classification } \\
\hline $\mathrm{A}$ & 2 & 8.3 & 22 & 91.7 & \multirow{3}{*}{15.58} & \multirow{3}{*}{$0.000 * *$} \\
\hline B & 6 & 60.0 & 4 & 40.0 & & \\
\hline $\mathrm{C}$ & 8 & 66.7 & 4 & 33.3 & & \\
\hline \multicolumn{7}{|l|}{ Sex } \\
\hline Male & 8 & 33.3 & 16 & 66.7 & & \\
\hline Female & 8 & 36.4 & 14 & 63.6 & & \\
\hline
\end{tabular}

*significant

** highly significant 
Table (3): Relation between hepatic venous waveform detected by Doppler US and some factors including age, sex, Child- Pugh classification, duration of liver cirrhosis and OV size.

\begin{tabular}{|c|c|c|c|c|c|c|c|c|}
\hline \multirow{2}{*}{$\begin{array}{l}\text { Total No = } 46 \\
\text { patients. }\end{array}$} & \multicolumn{2}{|c|}{ Mono } & \multicolumn{2}{|r|}{$\mathrm{Bi}$} & \multicolumn{2}{|r|}{ Tri } & \multirow{2}{*}{$X^{2}$} & \multirow{2}{*}{$\mathrm{P}$} \\
\hline & No 14 & $(30.4 \%)$ & No 20 & $(43.5 \%)$ & No 12 & $(26.1 \%)$ & & \\
\hline $\begin{array}{l}\text { Child- Pugh } \\
\text { classification }\end{array}$ & & & & & & & & $* *$ \\
\hline $\mathrm{A}$ & 7 & 29.2 & 5 & 20.8 & 12 & 50 & & \\
\hline B & 4 & 40.0 & 6 & 60.0 & 0 & 0.0 & 17.63 & 0.001 \\
\hline $\mathrm{C}$ & 3 & 25.0 & 9 & 75 & 0 & 0.0 & & \\
\hline \multicolumn{9}{|l|}{ Sex } \\
\hline Male & 9 & 37.5 & 13 & 54.2 & 2 & 8.3 & 8.2 & 0.1 \\
\hline Female & 5 & 22.7 & 7 & 31.8 & 10 & 45.5 & & \\
\hline \multicolumn{9}{|l|}{ Age } \\
\hline$<25$ & 5 & 29.4 & 6 & 35.3 & 6 & 35.3 & & \\
\hline $25-50$ & 4 & 21.1 & 9 & 47.4 & 6 & 31.6 & 5.62 & 0.22 \\
\hline $50+$ & 5 & 50.0 & 5 & 50.0 & 0 & 0.0 & & \\
\hline \multicolumn{9}{|l|}{$\begin{array}{l}\text { Duration of liver } \\
\text { cirrhosis /years }\end{array}$} \\
\hline$<4$ & 4 & 23.5 & 7 & 41.2 & 6 & 35.3 & & \\
\hline 4- 8 & 5 & 29.4 & 6 & 35.3 & 6 & 35.3 & 5.89 & 0.21 \\
\hline $8+$ & 5 & 41.7 & 7 & 58.3 & 0 & 0.0 & & \\
\hline \multicolumn{9}{|l|}{ OV-size } \\
\hline Small & 6 & 37.5 & 9 & 56.3 & 1 & 6.3 & 502 & 008 \\
\hline Large & 8 & 26.7 & 11 & 36.7 & 11 & 36.7 & .02 & 0.00 \\
\hline
\end{tabular}

** highly significant

Table (4): Validity of US hepatic venous waveform for the diagnosis of large OV.

\begin{tabular}{|l|c|c|c|c|c|c|c|c|}
\hline Total no=46 & $\begin{array}{c}\text { True } \\
+\mathrm{ve}\end{array}$ & $\begin{array}{c}\text { True } \\
-\mathrm{ve}\end{array}$ & Sensitivity & specificity & PPV & NPV & Kappa & P \\
\hline Waveform & 6 & 11 & $42.9 \%$ & $57.9 \%$ & 85.7 & 91.7 & 0.33 & $0.04 *$ \\
\hline Monophasic alone & 9 & 11 & $90.0 \%$ & $50.0 \%$ & 45.0 & 91.7 & 0.31 & $0.03 *$ \\
\hline $\begin{array}{l}\text { Biphasic alone } \\
\begin{array}{l}\text { Monophed } \\
\text { Biphasic. }\end{array}\end{array}$ & 15 & 11 & $93.8 \%$ & $36.7 \%$ & 44.1 & 91.7 & 0.24 & $0.02 *$ \\
\hline
\end{tabular}

*significant

\section{DISCUSSION}

$\mathrm{OV}$ bleeding in liver cirrhotic patients is a critical medical emergency associated with a high mortality rate [26]. Large $\mathrm{OV}$ is an additional risk factor that predicts impending variceal bleeding [27]. Non- invasive prediction of large $\mathrm{OV}$ is a stressing need to allow early medical or OGD interference in patients with impending variceal bleeding [28].

Our study showed that Large OV were significantly associated with longer duration of liver cirrhosis while small OV were significantly associated with shorter duration of liver cirrhosis. This can be explained by the time availability for the development of portal hypertension and the formation of large OV.
These results agree with those of Palmer [29] and Cales et. al., [30] who found that longer duration of liver cirrhosis was significantly, associated with the occurrence of large oesophageal varices.

Our study showed that large OV were more prevalent than small OV among Child-Pugh class $\mathrm{B} \& \mathrm{C}$ patients while small $\mathrm{OV}$ were more prevalent than large OV among Child-Pugh class A patients and the differences were highly significant. This means that large OV were more prevalent among patients with more severe liver disease while small OV were more prevalent among patients with less severe liver disease. This can be explained by the progressive increase in variceal wall tension with increased severity of liver disease and the eventual increase in portal hypertension. Our results agree with 
those of Zaman et. al., [31] and Cherian et. al., [28] who found that advanced Child-Pugh class and low platelet count were associated with the presence of large OV.

Our study showed that hepatic venous triphasic waves were more encountered than other waves among Child- Pugh class A patients while biphasic waves were the most encountered among Child- Pugh class B\&C patients. The differences were highly significant. This means that there was a relation between loss of hepatic venous triphasic waves and the severity of liver disease. This can be explained by the progressive decrease of hepatic compliance with the eventual increased severity of liver disease. This result agrees with that of Bhutto et. al., who found a significant relation between hepatic venous waveform pressure changes and the severity of hepatic dysfunction [32].

Our study showed that hepatic venous biphasic waves were the most encountered than other waves among patients with small OV, while monophasic waves were the least encountered among patients with large OV, however the differences were insignificant. The negative predictive values of biphasic and / or monophasic hepatic venous waveforms to diagnose large OV were very high that denote a poor agreement between loss of hepatic venous triphasic waves and the size of $\mathrm{OV}$ and that the loss of hepatic venous triphasic waves is a weak predictor of large OV. This result agrees with that of Bhutto et. al., [32] and Shabestari et. al., [33] who found an insignificant relation between hepatic venous waveform changes and the grading of oesophageal varices.

On the other hand, these results do not agree with those of Gorka et. al., [34] in a Saudi Arabian study, and Josepf et. al., [25] in an Indian study, who found that the loss of hepatic venous triphasic waves is a highly sensitive predictor of large OV. In the same direction Baik et. al., [35] - in their South Korean study- found that the assessment of Doppler US hepatic venous waveform is a useful non-noninvasive predictor of the severity of portal hypertension. This controversy can be attributed to many environmental, pathological and nutritional differences that can affect the pathogenesis of portal hypertension and hepatic venous waveform changes. The different inclusion and exclusion criteria could add to the different results such as studying patients with recent variceal bleeding while our study included only cirrhotic patients without previous history of variceal bleeding.

\section{CONCLUSION}

Loss of hepatic venous triphasic waves - detected by Color Doppler Ultrasound- is a weak predictor for the diagnosis of large $\mathrm{OV}$ in liver cirrhotic patients without history of variceal bleeding.

\section{Funding: Non.}

Conflicts of interest: The authors declare no conflict of interest.

\section{Ethical approval: Approved.}

\section{REFERENCES}

1. Giannini EG, Botta F, Borro P, Dulbecco P, Testa E, Mansi C, et al. Application of the platelet count/spleen diameter ratio to rule out the presence of oesophageal varices in patients with cirrhosis: a validation study based on follow-up. Dig Liver Dis. 2005; 37:779-85.

2. Pagliaro L, D’Amico G, Pasta L, Politi F, Vizzini G, Traina M. Portal hypertension in cirrhosis: Natural history. In: Bosch J, Groszmann RJ, editors. Portal Hypertension. Pathophysiology and Treatment. Oxford: Blackwell Scientific; 1994. pp. 72-92.

3. Zoli M, Merkel C, Donatella M, Marchesini G, Gatta A, Pisi E. Evaluation of a new endoscopic index to predict first bleeding from the upper gastrointestinal tract in patients with cirrhosis. Hepatology. 1996;24:1047-1052.

4. D'Amico G, De Franchis R, a cooperative study. Upper digestive bleeding in cirrhosis: Posttherapeutic outcome and prognostic indicators. Hepatology. 2003;38:599-612.

5. Garcia-Tsao G, Sanyal AJ, Grace ND, Carey W; Practice Guidelines Committe of the American Association for the Study of Liver Diseases; Practice Parameters Committee of the American College of Gastroenterology. Prevention and management of gastroesophageal varices and variceal hemorrhage in cirrhosis. Hepatology. 2007 ;46(3): 922-38.

6. de Franchis R. Evolving consensus in portal hypertension. Report of the Baveno IV consensus workshop on methodology of diagnosis and therapy in portal hypertension. J Hepatol 2005; 43:167-176. 
7. de Franchis R. Revising consensus in portal hypertension: report of the Baveno $\mathrm{V}$ consensus workshop on methodology of diagnosis and therapy in portal hypertension. J Hepatol 2010; 53:762-768.

8. Spiegel BM, Targownik L, Dulai GS, Karsan HA, Gralnek IM. Endoscopic screening for esophageal varices in cirrhosis: Is it ever cost effective? Hepatology. 2003;37(2): 366-77.

9. Schepis F, Camma C, Niceforo D, Magnano A, Pallio S, Cinquegrani $M$, et al. Which patients with cirrhosis should undergo endoscopic screening for esophageal varices detection? Hepatology. 2001;33(2): 333-8.

10. Qamar A A, Grace N D, Groszmann R J, Garcia Tsao G, Bosch J, Burroughs AK, et al. Platelet count is not a predictor of the presence or development of gastroesophageal varices in cirrhosis. Hepatology. 2008;47(1): 153-9.

11. Hong WD, Dong LM, Jiang ZC, Zhu QH, Jin SQ. Prediction of large esophageal varices in cirrhotic patients using classification and regression tree analysis. Clinics (Sao Paulo). 2011; 66(1): 119124.

12. Chalasani $\mathrm{N}$, Imperiale $\mathrm{TF}$, Ismail $\mathrm{A}$, Sood $\mathrm{G}$, Carey M, Wilcox CM, et al. Predictors of large esophageal varices in patients with cirrhosis. Am J Gastroenterol. 1999; 94(11): 3285-91.

13. Sharma SK, Aggarwal R. Prediction of large esophageal varices in patients with cirrhosis of the liver using clinical, laboratory and imaging parameters. J Gastroenterol Hepatol.2007; 22(11):1909-15.

14. Burton JR, Liangpunsakul S, Lapidus J, Giannini E, Chalasani N, Zaman A. Validation of a multivariate model predicting presence and size of varices. J Clin Gastroenterol. 2007;41(6): 609-15.

15. Hong WD, Zhu QH, Huang ZM, Chen XR, Jiang $\mathrm{ZC}$, $\mathrm{Xu} \mathrm{SH}$, et al. Predictors of esophageal varices in patients with $\mathrm{HBV}$ related cirrhosis: a retrospective study. BMC Gastroenterol. 2009;9:11.

16. Von Herbay A, Frieling $\mathrm{T}$, Haussinger $\mathrm{D}$. Association between duplex Doppler sonographic flow pattern in right hepatic vein and various liver diseases. J Clin Ultrasound. 2001;29(1):2530 .

17. Farrant P, Meire HB. Hepatic vein pulsatility assessment on spectral Doppler ultrasound. $\mathrm{Br} J$ Radiol. 1997;70:829-32.
18. Dietrich CF, Lee JH, Gottschalk R, Herrmann G, Sarrazin C, Caspary WF, et al. Hepatic and portal vein flow pattern in correlation with intrahepatic fat deposition and liver histology in patients with chronic hepatitis C. Am J Roentgenol. 1998; 171(2):437-43.

19. Kok T, van der Jagt EJ, Haagsma EB, Bijleveld CM, Jansen PL, Boeve WJ. The value of Doppler ultrasound in cirrhosis and portal hypertension. Scand J Gastroenterol Suppl. 1999;230:82-8.

20. Colli A, Cocciolo M, Riva C, Martinez E, Prisco A, Pirola M, et al. Abnormalities of Doppler waveform of the hepatic veins in patients with chronic liver disease: Correlation with histologic findings. Am J Roentgenol. 1994;162:833-7.

21. Ohta M, Hashizume M, Tomikawa M, Ueno K, Tanoue K, Sugimachi K. Analysis of hepatic vein waveform by Doppler ultrasonography in 100 patients with portal hypertension. Am $J$ Gastroenterol. 1994;89:170-175.

22. Ohta M, Hashizume M, Kawanaka H, Akazawa $\mathrm{K}$, Tomikawa M, Higashi $\mathrm{H}$, et al. Prognostic significance of hepatic vein waveform by Doppler ultrasonography in cirrhotic patients with portal hypertension. Am J Gastroenterol. 1995;90:1853-57.

23. Abu-Yousef MM. Normal and respiratory variations of the hepatic and portal venous duplex Doppler waveforms with simultaneous electrocardiographic correlation. J Ultrasound Med. 1992;11:263-268.

24. Garcia-Tsao G, Sanyal AJ, Grace ND, Carey WD; Practice Guidelines Committee of the American Association for Study of Liver Diseases; Practice Parameters Committee of the American College of Gastroenterology. Prevention and management of gastroesophageal varices and variceal hemorrhage in cirrhosis. $A m$ J Gastroenterol. 2007b ;102(12): 2086-2102.

25. Joseph T, Madhavan M, Devadas K, Ramakrishnannair VK. Doppler Assessment of Hepatic Venous Waves for Predicting Large Varices in Cirrhotic Patients. Saudi $J$ Gastroenterol. 2011;17(1):36-39.

26. Witzel L, Wolbergs E, Merki H. Prophylactic endoscopic sclerotherapy of esophageal varices: a prospective controlled study. Lancet 1985; 1(8432): 773-775.

27. North Italian Endoscopic Club for the Study and Treatment of Esophageal Varices. Prediction of first variceal hemorrhage in patients with cirrhosis of the liver and esophageal varices: a prospective multicenter study. $N$ Eng $J$ Med. 1988; 319: 983- 989. 
28. Cherian JV, Deepak N, Ponnusamy RP, Somasundaram A, Jayanthi V. Non-invasive Predictors of Esophageal Varices. Saudi $J$ Gastroenterol. 2011; 17(1): 64-68.

29. Palmer ED. On the natural history of esophageal varices which are secondary to portal cirrhosis. Ann Intern Med. 1957; 47: 18-26.

30. Cales P, Desmorat H, Vinel JP, Caucanas JP, Ravaud A, Gerin P, et al. Incidence of large oesophageal varices in patients with cirrhosis: application to prophylaxis of first bleeding. Gut, 1990, 31, 1298-1302.

31. Zaman A, Becker T, Lapidus J, Benner K. Risk Factors for the Presence of Varices in Cirrhotic Patients Without a History of Variceal Hemorrhage.Arch Intern Med. 2001;161:25642570 .

32. Bhutto AR, Abbasi A, Butt N, Khan A, Munir SM. Hepatic vein waveform in liver cirrhosis: correlation with child's class and size of varices. $J$ Pak Med Assoc. 2012 ; 62(8):794-7.
33. Shabestari A, Nikoukar E, Bakhshandeh $H$. Hepatic doppler ultrasound in assessment of the severity of esophageal varices in cirrhotic patients: Iran. J Radiol Spring. 2007;4(3):151-8.

34. Gorka W, Al Mulla A, Al Sebayel M, Altraif I, Gorka TS. Qualitative Hepatic Venous Doppler Sonography Versus Portal Flowmetry in Predicting the Severity of Esophageal Varices in Hepatitis C Cirrhosis. AJR 1997; 169(2): 511515.

35. Baik S K , Kim J W , Kim H S , Kwon S O, Kim Y J, Park J W, et al. Recent Variceal Bleeding: Doppler US Hepatic Vein Waveform in Assessment of Severity of Portal Hypertension and Vasoactive Drug Response. Radiology. 2006; 240, 574-580.

Peer reviewer: J G Freeman, Liver unit, Royal Derby Hospital, Derby, UK. Talaat Fathy , Assistant professor of Tropical Medicine and Hepatogastroenterology, Faculty of Medicine, Zagazig University, Egypt.

Editor: Mohamed Emara, Lecturer of Tropical Medicine and Hepatogastroenterology, Faculty of Medicine, Zagazig University, Egypt. 